\title{
Rheological characterization of A201 aluminum alloy
}

\author{
A. BLANCO, Z. AZPILGAIN, J. LOZARES, P. KAPRANOS, I. HURTADO
}

Mechanical and Manufacturing Department, Faculty of Engineering, Mondragon Unibertsitatea, Loramendi 4, 20500 Arrasate, Spain

Received 13 May 2010; accepted 25 June 2010

\begin{abstract}
The thermodynamic characterization as well as the rheological characterization of the A201 alloy were conducted. Thermodynamic simulations (CALPHAD method) and calorimetric experiments were performed to determine the solidus and liquidus temperatures, the melting range and the sensitivity of the solid fraction at the thixoforming temperatures. The rheology of aluminium alloy A201 was examined using a high temperature Searle rheometer. The flow behaviour was analyzed with concentric cylinders of graphite to avoid chemical interactions with the liquid or semi-solid aluminium. The rotational body was grooved to prevent a phenomenon called wall slippage. Continuous cooling experiment was used to observe the shear rate effects on the flow behaviour. It can be seen that the viscosity level decreases at higher shear rates. Shear rate jump experiment was carried out to evaluate the steady state flow curve within the analyzed shear rate range from $60 \mathrm{~s}^{-1}$ to $260 \mathrm{~s}^{-1}$. It is found that the power law indexes are -1.35 and -1.49 for $35 \%$ and $45 \%$ solid fraction, respectively. Finally, some mechanical property data of as-cast and as-thixoformed A201 alloy are included indicating the potential for high strength applications.

Key words: aluminum alloys; rheology; mechanical properties; semi-solid metal; tixotropy; shear-thinning
\end{abstract}

\section{Introduction}

Semi-solid forming is the shaping of materials in a temperature between the solidus and liquidus temperatures. In early 1970 s, SPENCER et al[1] investigated the hot tearing of some foundry alloys in semi-solid range with a rotational Couette type viscometer. They found that when shearing the material during the solidification process, spherical solid particles were formed instead of typical dendritic solidification structures and they showed that the behaviour of semi-solid metals was shear thinning and tixotropic.

Semi-solid alloys used in thixoforming processes exhibit complex non-Newtonian flow behaviour (e.g. shear thinning, time-dependent effects, viscoelasticity, yield stress) with dependence on temperature history and stress history[2]. This behaviour can be exploited for manufacturing, because when an alloy has a nondendritic microstructure in the semi-solid state, it can be forced to fill a die[3]. In this sense, semi-solid forming is an emerging technology that has allowed the production of security components using aluminum alloys[4].

The alloy investigated in this study is the aluminum alloy A201. This alloy is an important commercial alloy, because it has high mechanical properties, excellent machinability and good formability. It is commonly used in aerospace parts and it is also suitable for semi-solid applications due to its wide solidification range. The A201 alloy has a particularly high response to age-hardening, because silver completely changes the precipitation process, causing orthorhombic form of the tetragonal phase $\theta\left(\mathrm{Al}_{2} \mathrm{Cu}\right)$ to precipitate as very thin plates on the $\{111\}$ matrix planes rather than $\{100\}$ planes[5].

The present work is focused on the thermodynamic characterization as well as the rheological characterization of A201 alloy. Thermodynamic simulations and calorimetric experiments have been performed in order to know the solid fraction vs temperature curves. In this sense, the knowledge of the relation between the solid fraction and the temperature is of major importance for experimental evaluation and modelling[6]. Rheological tests are carried out in order to analyze the flow behaviour of the material. Finally, some mechanical property data of as-cast and as-thixoformed A201 alloy are included indicating the potential for high strength applications.

Corresponding author: A. BLANCO; Tel: +34-943794700; E-mail: ablanco@eps.mondragon.edu 


\section{Experimental}

The chemical composition of the alloy analyzed in this study is shown in Table 1.

Table 1 Composition of A201alloy (mass fraction, \%)

\begin{tabular}{ccccc}
\hline $\mathrm{Al}$ & $\mathrm{Cu}$ & $\mathrm{Ag}$ & $\mathrm{Mn}$ & $\mathrm{Mg}$ \\
\hline Bal. & 4.53 & 0.15 & 0.35 & 0.32 \\
\hline
\end{tabular}

The relation between the solid fraction and temperature was calculated by calorimetric tests and thermodynamic simulations. The DSC (differential scanning calorimetry) analyses were carried out in an argon atmosphere with a scanning rate of $5^{\circ} \mathrm{C} / \mathrm{min}$. The thermodynamic simulations were carried out with the software FactSage along with the GTT Light Metal Alloys database. The heat flow vs temperature curves were used to calculate the solidus and liquidus temperatures, the melting range and the sensitivity of the solid fraction at the thixoforming temperatures.

The rheological experiments were performed with a high-temperature Searle type rheometer (Fig.1). To measure the flow behavior, a graphite concentric cylinders device was used. The graphite avoided chemical interactions with the liquid or semi-solid aluminum. The rotational body was grooved to prevent phenomenon called wall slippage which could occur in suspensions and could lead to incorrect rheological measurements.

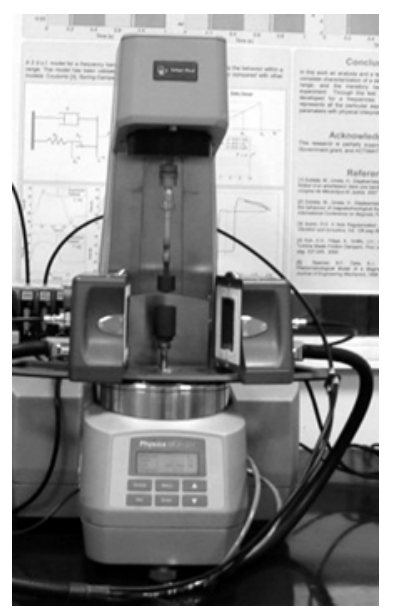

Fig.1 High-temperature Searle type rheometer MCR501

Two different series of experiments were carried out: cooling experiments and isothermal experiments. In the first series of experiments, the alloy was heated up above the liquidus temperature and then the melt was cooled down with a constant cooling rate and constant shear rate, meanwhile the apparent viscosity was measured. This experiment was repeated with different shear rates.
In the second series of experiments, the molten alloy was cooled down continuously with a cooling rate of $5{ }^{\circ} \mathrm{C} / \mathrm{min}$ under constant shearing until the desired solid fraction was reached. After the final solid fraction was achieved, the alloy was sheared isothermally for $1 \mathrm{~h}$. This stage was called material preparation. Once the material was ready, shear rate jump experiments were carried out to investigate the shear thinning and thixotropic behavior. This experiment was repeated for different solid factions.

Finally, some mechanical property data of as-cast and as-thixoformed A201 alloy were compared. Conventional DC-cast dendritic material was re-cast using a cooling slope (CS) in order to obtain feedstock having the necessary non-dendritic, near spheroidal microstructure for thixoforming. For A201 alloy, conventional $\mathrm{T} 6$ and $\mathrm{T} 7$ heat treatments were used.

\section{Results and discussion}

\subsection{Thermodynamic characterization}

By taking into account that the molten alloy is cooled down until desired solid fraction, the cooling curve is considered in the calorimetric test.

Fig. 2 shows the solid fraction vs temperature curve and the heat flow of the A201 alloy calculated by differential scanning calorimetry (DSC) during cooling at $5{ }^{\circ} \mathrm{C} / \mathrm{min}$.

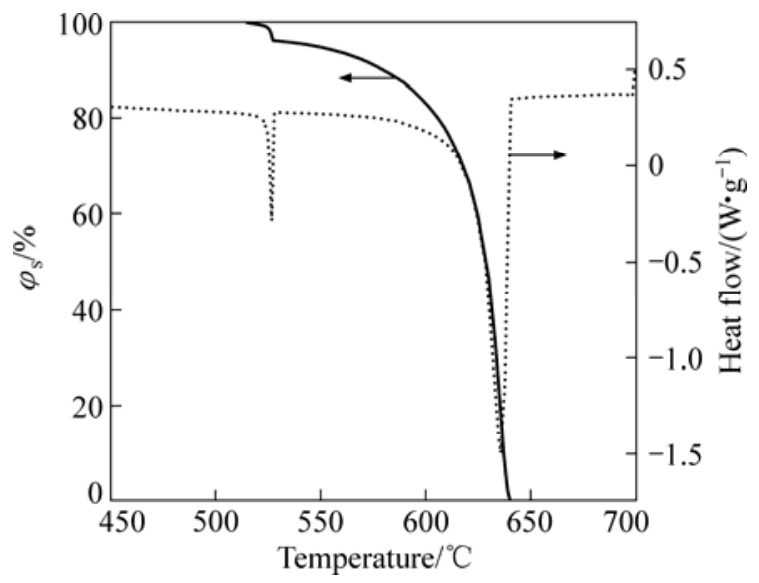

Fig.2 Solid fraction and heat flow vs temperature curves of A201 alloy calculated by calorimetric experiments (cooling at 5 ${ }^{\circ} \mathrm{C} / \mathrm{min}$ )

Fig. 3 shows the solid fraction vs temperature curves calculated by DSC cooling and thermodynamic simulations performed in equilibrium and nonequilibrium (Scheil) conditions with FactSage.

Table 2 summarizes the thermodynamic parameters of the A201 alloy. It can be seen that the thermodynamic simulations have shown a good agreement with DSC results. 


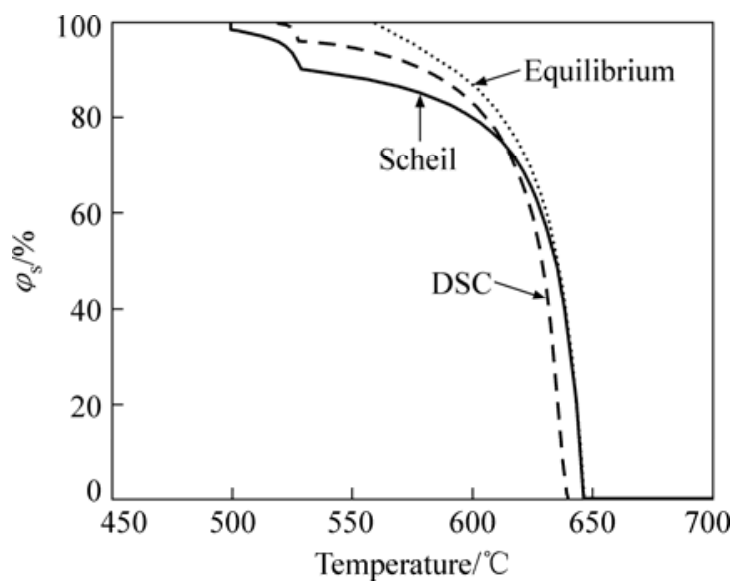

Fig.3 Fraction solid vs temperature relationship calculated by DSC curves, thermodynamic simulations in equilibrium and non equilibrium (Scheil) by FatSage software

Table 2 Thermodynamic parameters of A201 alloy

\begin{tabular}{|c|c|c|c|c|c|c|}
\hline \multirow{2}{*}{ Method } & \multicolumn{3}{|c|}{ Solidification range } & \multicolumn{3}{|c|}{ Sensitivity } \\
\hline & $t_{\mathrm{L}} /{ }^{\circ} \mathrm{C}$ & $t_{\mathrm{s}} /{ }^{\circ} \mathrm{C}$ & $\Delta t_{\mathrm{LS}} /{ }^{\circ} \mathrm{C}$ & $t /{ }^{\circ} \mathrm{C}$ & $\varphi_{\mathrm{s}} \mathrm{s} \%$ & $\left|\mathrm{~d} \varphi_{\mathrm{s}} / \mathrm{d} T\right|$ \\
\hline \multirow{2}{*}{ DSC } & \multirow{2}{*}{640} & \multirow{2}{*}{514} & \multirow{2}{*}{126} & 632.7 & 35 & 0.0506 \\
\hline & & & & 630.3 & 45 & 0.0354 \\
\hline \multirow{2}{*}{$\begin{array}{c}\text { Scheil } \\
\text { (Simulation) }\end{array}$} & \multirow{2}{*}{646.3} & \multirow{2}{*}{499.3} & \multirow{2}{*}{147} & 639.8 & 35 & 0.0357 \\
\hline & & & & 636.6 & 45 & 0.0260 \\
\hline \multirow{2}{*}{$\begin{array}{l}\text { Equilibrium } \\
\text { (Simulation) }\end{array}$} & \multirow{2}{*}{646.4} & \multirow{2}{*}{558.2} & \multirow{2}{*}{88.4} & 640.2 & 35 & 0.0392 \\
\hline & & & & 637.2 & 45 & 0.0295 \\
\hline
\end{tabular}

\subsection{Rheological characterization}

\subsubsection{Cooling experiments}

The non-isothermal experiments consist of continuous cooling experiments at constant shear rates. This experimental technique is a simple method to characterize the rheology of the alloy at certain solid fractions[6].

Fig. 4 shows the viscosities versus solid fraction at different shear rates for the aluminum alloy A201. The shear rate range is varied between $50 \mathrm{~s}^{-1}$ and $250 \mathrm{~s}^{-1}$. The

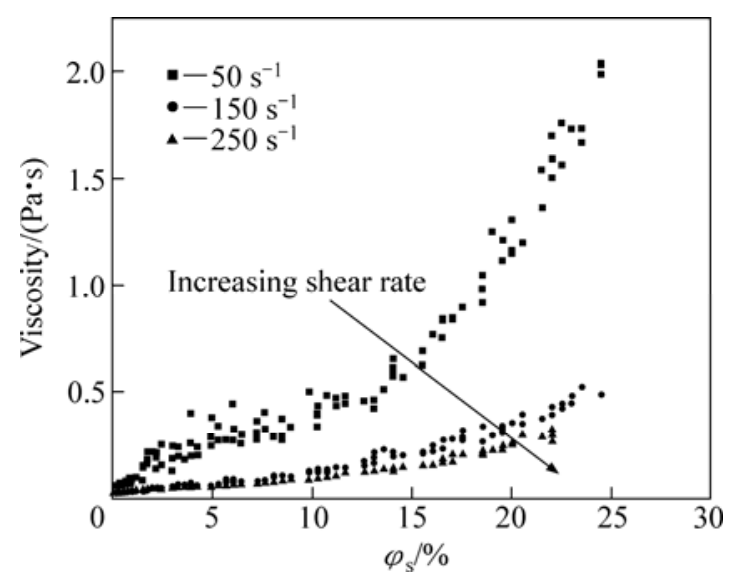

Fig.4 Viscosity versus solid fraction at different shear rates for A201 alloy solid fraction is calculated by calorimetric test.

It can be seen that all curves appear as an exponential functions and that the viscosity level decreases at higher shear rates. In all cases, the viscosity increases with decreasing temperature (increasing solid fraction).

At lower shear rates, the state of agglomeration is substantial, a considerable fraction of liquid is immobilized and the viscosity is high. With increasing shear rates, the agglomerates break up into smaller particles with less entrapped liquid, and a low viscosity is found[7-8]. Therefore, the lower viscosities indicate the non-Newtonian flow behaviour of semi-solid alloys and a better mobility of the solid-phase particles, probably resulting from larger particle diameters and smoother shapes[6].

\subsubsection{Isothermal experiments}

The relation between temperature and solid fraction comes from calorimetric test (Table 2). Solid fractions of $35 \%\left(t=632.7{ }^{\circ} \mathrm{C}\right)$ and $45 \%\left(t=630.3{ }^{\circ} \mathrm{C}\right)$ have been considered.

After the alloy is completely melted at $700{ }^{\circ} \mathrm{C}$, the liquid alloy is cooled down continuously with a cooling rate of $5{ }^{\circ} \mathrm{C} / \mathrm{min}$ under constant shearing $\left(100 \mathrm{~s}^{-1}\right)$ until the specified solid fraction is reached. During isothermal holding, the viscosity decreases continuously as a result of continued globularization and Ostwald ripening until a "steady state" is reached[8-9]. The steady state value of the viscosity depends on the shear rate and solid fraction[8].

After the material preparation stage, the shear rate jump experiments are performed in order to evaluate the shear thinning and thixotropic behavior. The shear rate jump experiments are performed for shear rates between 60 and $260 \mathrm{~s}^{-1}$ for two different solid fractions.

The apparent viscosity versus time is plotted in Fig.5 at different solid fractions. As can be seen in Fig.5, the A201 alloy is thixotropic (with its apparent

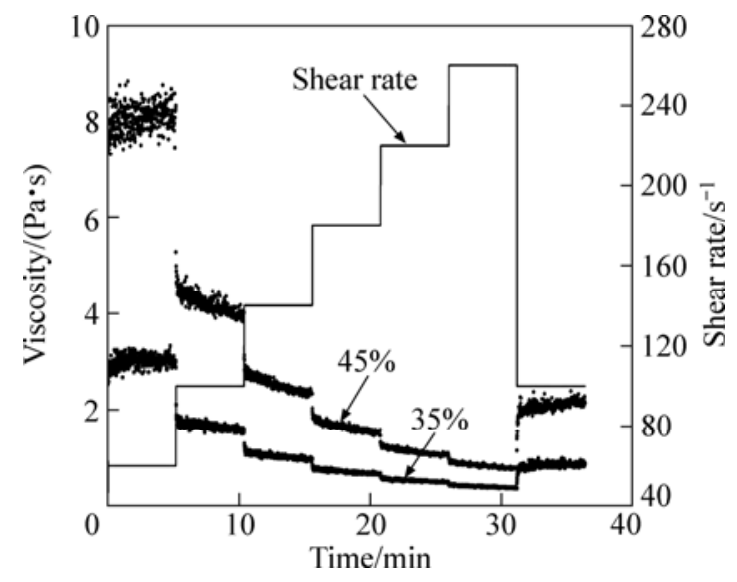

Fig.5 Shear rate jump test results for $35 \%$ and $45 \%$ solid fractions of A201 alloy 
viscosity decreasing continuously with time under shear) and shows shear thinning behavior (with its apparent viscosity decreasing as the shear rate increases).

For non-Newtonian suspensions, the viscosity can be expressed as a function of shear rate. The power law equation (Ostwald equation) is the best suited for many shear thinning fluids[7-8, 10-11]:

$\eta=K \dot{\gamma}^{m}$

where $\dot{\gamma}$ is the shear rate and $m$ is the power law index. The power law index $m$ is negative for shear thinning materials.

After performing the shear rate jump test, the steady state viscosities are recorded as a function of shear rate. As a result, steady state flow curves can be generated (Fig.6) and the values are fitted to Eq.(1). Power law indexes of -1.35 and -1.49 for $35 \%$ and $45 \%$ solid fraction are found, respectively.

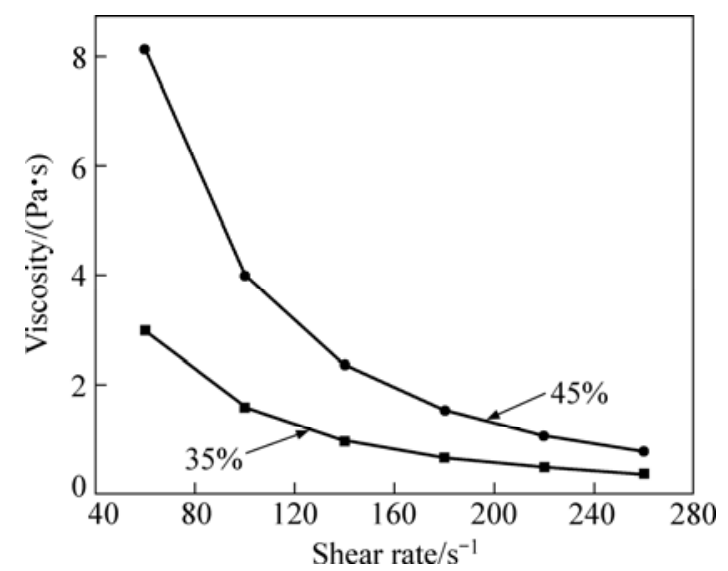

Fig.6 Steady state flow curves for A201 alloy with 35\% and $45 \%$ solid fractions

\subsection{Mechanical properties}

Although this alloy is difficult to cast, it has a particularly high response to age-hardening and therefore offers mechanical properties close to the wrought 2014 alloy.

Conventional DC-cast dendritic material was re-cast using a cooling slope (CS) of $200 \mathrm{~mm}$ in length positioned at an angle of $450^{\circ}$ in order to obtain feedstock having the necessary non-dendritic, near spheroidal microstructure for thixoforming. A number of billets were cast using the CS, with the A201 alloy superheated by $40{ }^{\circ} \mathrm{C}$ above the released temperature of $670{ }^{\circ} \mathrm{C}$. These billets were machined into slugs with length and diameter of $60 \mathrm{~mm}$ to be used for thixoforming flat products for further mechanical testing using the die shown in Fig.7.

The thixoformed fingers were X-ray scanned and the hardness measurements were obtained in the as-thixoformed condition as well as the post heat

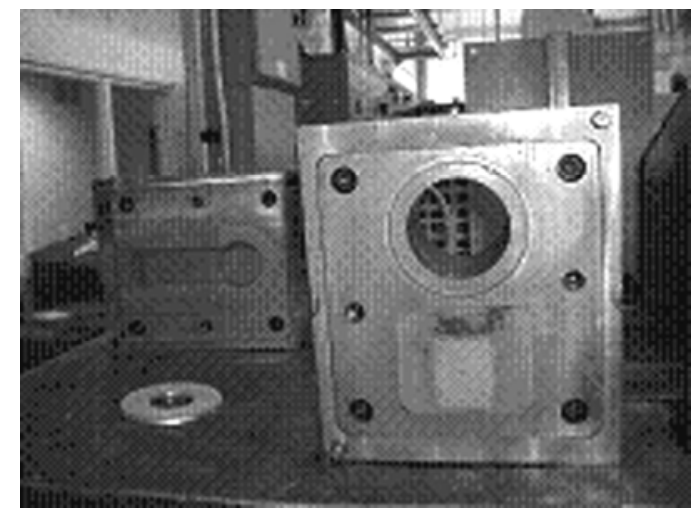

Fig.7 Die used for thixoforming, featuring a steel base and replaceable inserts with single finger cavity used

treatment condition.

For alloy A201, a conventional T6 heat treatment (two step solution treatment for $2 \mathrm{~h}$ at $513{ }^{\circ} \mathrm{C}$ and for 17 $\mathrm{h}$ at $527{ }^{\circ} \mathrm{C}$ followed by water quenching and then ageing for $20 \mathrm{~h}$ at $153{ }^{\circ} \mathrm{C}$ ) has been used; in addition, a $\mathrm{T} 7$ treatment that differs only in the ageing treatment, $5 \mathrm{~h}$ at $190{ }^{\circ} \mathrm{C}$ has also been conducted. From each thixoforging, it was possible to obtain two tensile test specimens.

The UTS and elongation of the thixoformed A201 products appear better than those of the cast alloy, especially the nearly doubled elongation values in the T6 and $\mathrm{T} 7$ heat treated conditions (Table 3).

Table 3 Average mechanical properties of A201alloy

\begin{tabular}{ccc}
\hline State & UTS/MPa & Elongation/\% \\
\hline As-cast & 480 & 6.5 \\
As-thixoformed & 490 & 11 \\
\hline
\end{tabular}

These values are comparable with the values of wrought alloy A2014. In addition, initial fatigue tests of thixoformed A201 specimens have yielded very promising results[12]. In addition, the current series of mechanical properties data for thixoformed A201 have been obtained by using non-dendritic feedstock generated by the non-efficient cooling slope process. It is expected that specimens will be generated by utilizing feedstock obtained by the magneto- hydrodynamic stirring (MHD) and the new rheocasting (NRC) processes can result in even better properties, bringing the acceptance of thixoformed A201 alloy parts in the aerospace industry one step closer to reality.

\section{Conclusions}

1) The A201 alloy has a particularly high response to age-hardening and therefore offers mechanical 
properties close to the wrought 2014 alloy.

2) After the thermodynamic characterization, it is found that the values of sensitivity at temperatures where the forming process takes places are larger than the optimum values proposed by FAN et al $\left(0.015{ }^{\circ} \mathrm{C}^{-1}\right)$. This makes it difficult to reach a stable and robust process in semisolid state.

3) The rheological behavior of A201 was performed with a high-temperature Searle type rheometer. The experimental results show that the behavior of the alloy is pseudoplastic and tixotropic. Shear rate jump experiment was carried out to evaluate the steady state flow curve within the analyzed shear rate range from 60 to $260 \mathrm{~s}^{-1}$. It is found that the power law indexes are -1.35 and -1.49 for $35 \%$ and $45 \%$ solid fraction, respectively. Steady state viscosities indicate that A201 alloy shows strongly shear thinning behavior.

4) The objective of the near future is to continue the rheological characterization. In this sense, yield stress and isostructural experiment of A201 alloy will be performed in order to complete the rheological characterization and to carry out the rheological simulation.

\section{Acknowledgements}

The authors would like to thank the "Ministerio de Ciencia e Innovación" and to the "Fondos FEDER", project "Integrauto" PSE-370000-2008-03, and to the Basque Government, project "ETORTEK, Manufacturing 0.0 II", for their financial support. One of the authors, Ainara BLANCO, thanks the Basque Government for the predoctoral fellowship.

\section{References}

[1] FLEMINGS M C. Behavior of metal alloys in the semisolid state [J].
Metallurgical and Materials Transactions A, 1991, 22(5): 957-981.

[2] MODIGELL M, PAPE L, VASILIC K. Couette rheometry: Direct analysis vs inverse parameter determination [J]. Diffusion and Defect Data Pt. B: Solid State Phenomena, 2008, 141/142/143: 331-335.

[3] ATKINSON H V. Modelling of semi-solid processing [M]. Aachen: Shaker, 2008

[4] AZPILGAIN Z, HURTADO I, ORTUBAY R, LANDA I, ATXA J. Semisolid forging of 7000 series aluminum alloys $[\mathrm{M}] / / \mathrm{KANG} \mathrm{C} \mathrm{G}$, KIM S K, LEE S Y. Solid State Phenomena. Trans Tech Publications Ltd., 2006: 758-761.

[5] LIU D, ATKINSON H V, KAPRANOS P, JONES H. Effect of heat treatment on properties of thixoformed high performance 2014 and 201 aluminium alloys [J]. Journal of Materials Science, 2004, 39(1): 99-105.

[6] MODIGELL M, KOKE J. Time-dependent rheological properties of semi-solid metal alloys [J]. Mechanics of Time-Dependent Materials, 1999, 3(1): 15-30.

[7] JOLY P A, MEHRABIAN R. The rheology of a partially solid alloy [J]. Journal of Materials Science, 1976, 11: 1393-1418.

[8] QUAAK C J, HORSTEN M G, KOOL W H. Rheological behaviour of partially solidified aluminium matrix composites [J]. Materials Science and Engineering A, 1994, 183(1/2): 247-256.

[9] POLA A, ROBERTI R, MODIGELL M, PAPE L. Rheological characterization of a new alloy for thixoforming [J]. Diffusion and Defect Data Pt. B: Solid State Phenomena, 2008, 141/142/143: 301-306.

[10] BRABAZON D, BROWNE D J, CARR A J. Experimental investigation of the transient and steady state rheological behaviour of Al-Si alloys in the mushy state [J]. Materials Science and Engineering A, 2003, 356(1/2): 69-80.

[11] MOON H K. Rheological behavior and microstructure of ceramic particulate/aluminum alloy composites [D]. Boston: Massachusetts Institute of Technology, 1990.

[12] WABUSSEG H, GULLO G C, KAUFMANN H, UGGOWITZER P J. Properties of AlMgSi1 wrought alloy components produced by means of the NRC-process [C]// International Conference on Processing Material for Properties. San Francisco, 2000.

(Edited by YANG Bing) 